\title{
Gravidez na Adolescência e Construção de um Projeto de Vida
}

\author{
Sara Kudlowiez \\ Hospital de Clínicas/UFPR \\ Curitiba, PR, Brasil \\ Roberta Kafrouni \\ Universidade Tuiuti do Paraná \\ Curitiba, PR, Brasil
}

\begin{abstract}
RESUMO
O objetivo deste trabalho foi compreender os projetos de vida de um grupo de adolescentes grávidas, investigando quais eram esses projetos antes de as jovens engravidarem e quais os seus planos futuros depois de gravidez se confirmar. Participaram da pesquisa, 16 jovens grávidas, entre 13 e 19 anos, que residiam em Curitiba-PR e eram atendidas em ambulatório de pré-natal em maternidade do SUS. Os cuidados éticos foram observados. Foram utilizadas, como instrumento de pesquisa, entrevistas semiestruturadas, com perguntas baseadas em roteiro que contemplou temas sobre a gravidez na adolescência, tais como: a reação das adolescentes e de suas famílias à gravidez, os projetos de vida dessas adolescentes antes de terem engravidado, seus projetos de vida após a constatação da gravidez; entre outros. As entrevistas foram gravadas, transcritas e, posteriormente, submetidas à análise de conteúdo. Percebeu-se que a maioria das futuras mães não planejou a gravidez, nem tinha pensado sobre suas prováveis repercussões. Os projetos de vida anteriores à gravidez mostraram-se ausentes ou vagamente estruturados - "estudar e trabalhar" enquanto as consequências da nova realidade não eram percebidas com nitidez pelas jovens. Esse fato pode estar relacionado à qualidade precária do ensino público, que não proporciona ferramentas necessárias para que os alunos desenvolvam a capacidade de abstração e o senso crítico, de modo a elaborar estratégias viáveis para alcançar seus objetivos. Paralelamente, essas adolescentes enfrentam dificuldades no interior de suas famílias e comunidades, que geralmente não lhes fornecem elementos e oportunidades para construir projetos de vida inovadores. Conclui-se que condições como o contexto educacional, social e histórico podem ajudar a compreender a falta de projetos de vida mais autênticos e consistentes.
\end{abstract}

Palavras-chave: Projeto de vida; adolescência; gravidez na adolescência; psicologia sócio-histórica.

\section{ABSTRACT}

\section{Adolescent Pregnancy and Building a Life Project}

The objective in this study was to understand the life projects of a group of pregnant adolescents, investigating what those projects were before the young women became pregnant and what their future plans are after the pregnancy was confirmed. The research involved 16 pregnant adolescents, between 13 and 19 years old, who lived in Curitiba-PR and were assisted in out patient prenatal care in a maternity of SUS. Ethical guidelines were followed. The semi-structured interview technique was used with questions based on a script that included topics about teenage pregnancy, such as the reaction of the teenagers and their families to pregnancy, the plans which these adolescents have made before they became pregnant, their life projects after the confirmation of the pregnancy, among others. The interviews were recorded, transcribed and then submitted to content analysis. It was noticed that most of the young future mothers did not plan their pregnancy, and had not even thought about its probable repercussions. Their life projects before pregnancy proved to be absent or with a loose structure - " to study and to work "- while they did not clearly perceive the consequences of the new reality. This fact may be related to the poor quality of the public education, which does not provide the means for the students to develop their capacity of abstraction and critical thinking, in order to elaborate their abilities to construct feasible strategies to achieve their goals. Moreover, these teenagers face difficulties within their families and communities, which usually do not provide them with information and opportunities to create innovative projects of life. It was concluded that conditions such as educational, historical and social contexts could help us to understand the lack of authentic and consistent projects of life.

Keywords: Life project; adolescence; teenage pregnancy; socio-historical psychology.

\section{RESUMEN}

\section{Embarazo en la Adolescencia y Creación de Proyectos de Vida}

El objetivo de este estudio fue conocer los proyectos de vida de un grupo de adolescentes embarazadas, investigando lo que esos proyectos eran antes las jóvenes se quedaren embarazadas y cuáles son sus planes para el futuro después que el embarazo se há confirmado. En la investigación participaron 16 adolescentes embarazadas, entre 13 y 19 años, que vivían en Curitiba-PR y fueron atendidas em uma unidad de atención prenatal ambulatoria de una maternidad del SUS. 
Se siguieron las normas éticas. Se utilizó la técnica de entrevistas semi-estructuradas con preguntas basadas en un guión que incluyó temas sobre el embarazo en adolescentes, tales como la reacción de las adolescentes y sus familias con el embarazo, los planes que las adolescentes habiann hecho antes de quedarse embarazadas, sus proyectos de vida después de la confirmación del embarazo, entre otros. Las entrevistas fueron grabad, transcritas y luego sometidas a análisis de contenido. Se observó que la mayoría de las jóvenes futuras madres no planearon su embarazo, y además, ni siquiera habían pensado en las posibles repercusiones. Sus proyectos de vida antes del embarazo resultaron ser ausentes o vagamente estructurados - "Estudiar y trabajar" -, mientras que las consecuencias de la nueva realidad no eran claramente percibidas por ellas. Este hecho puede estar relacionado con la mala calidad de la educación pública, que no proporciona los medios para que los estudiantes desarrollen su capacidad de abstracción y el pensamiento crítico, con el fin de elaborar sus habilidades para construir estrategias viables para lograr sus metas. Por otra parte, essas adolescentes se enfrentan a dificultades en sus familias y comunidades, que por lo general no les proporcionan información y oportunidades para crear proyectos innovadores en sus vidas. Se concluyó que las condiciones tales como los contextos educativos, históricos y sociales podrían ayudar a comprender la falta de proyectos auténticos y coherentes de vida.

Palabras clave: proyecto de vida; la adolescencia; embarazo en la adolescencia; psicología sociohistórica.

\section{INTRODUÇÃO}

A gravidez não planejada na adolescência é, em geral, considerada um problema, pois a ela estão associados diversos riscos biológicos e sociais. Entretanto, esta tem sido vista por alguns autores como uma alternativa legítima de projeto de vida ao alcance das jovens futuras mães (Belo \& Silva, 2004; Carvalho, Merighi, \& Jesus, 2009; Dadoorian, 2003; Joffily \& Costa [s.d.]; Loss \& Sapiro, 2005; Nascimento, 2006; Pantoja, 2003; Rangel \& Queiroz, 2008). Este artigo se propõe a aprofundar o entendimento dessa questão a partir da análise dos projetos de vida de adolescentes grávidas atendidas em uma maternidade pública na cidade de Curitiba, adotando a abordagem da Psicologia Sócio-Histórica, que se contrapõe às ideias naturalizadoras do pensamento liberal, ainda influentes na psicologia tradicional, mesmo nos dias de hoje (Bock, 2009).

O objetivo deste de trabalho foi compreender o projeto de vida de um grupo de adolescentes grávidas, para tanto, a elas foi perguntado, depois de a gravidez estar confirmada, que expectativas de futuro tinham antes de saberem que estavam grávidas, e quais nutriam após o advento da gravidez. Posteriormente, questionou-se às entrevistadas, se a gravidez fazia parte de seus projetos de vida. Para que se possa falar de projeto de vida de adolescentes grávidas, é necessário, inicialmente, abordar os próprios conceitos de adolescência e de projeto de vida, para depois verificar como a gravidez se relaciona com ambos.

Começando pelo conceito de adolescência, segundo Kafrouni (2009), diferentes concepções de juventude e adolescência podem ser identificadas na literatura acadêmica. A autora comenta que, no século XVII, houve um processo de idealização da juventude, como um período da vida no qual a beleza, força física e alegria de viver eram características essenciais. Tal idealização levou a uma formalização conceitual do próprio termo fortemente influenciada pelas modificações da estrutura familiar típicas do início da modernidade. Em relação à situação dos adolescentes no Brasil, Kafrouni (2009) ressalta que a diferença de classes é relevante na forma desigual com que a adolescência é vivenciada no país, uma vez que as grandes diferenças de renda e, em consequência, de oportunidades restringem o acesso da maior parte da população a bens essenciais como escolarização, lazer, cultura, trabalho e circulação nas cidades. Pode-se afirmar que a adolescência é um período da vida construído socialmente e não uma fase de desenvolvimento meramente natural. Além disso, dado que é fruto de contingências sociais, não pode ser concebida como um fenômeno universal, ao contrário, diferencia-se de acordo com a cultura e a classe social nas quais os jovens estão concretamente inseridos.

No mesmo sentido, Ozella (2003) afirma que o comportamento dos jovens deve ser compreendido como resultado de relações sociais, que decorrem, por sua vez, de valores socioculturais adquiridos pelos jovens na sua convivência com a família e comunidade. A adolescência não deve, portanto, ser compreendida como um período natural do desenvolvimento de uma pessoa, mas como uma representação social e psicológica de um conceito apreendido a partir de uma contextualização social e histórica, subordinase, assim, às peculiares vicissitudes e possiblidades dos seus sujeitos concretos; sob essa perspectiva, e de acordo com as pesquisas apresentadas neste trabalho, pode-se concluir que a gravidez na adolescência é sobredeterminada por fatores de ordem social, econômica, educacional e psicológica. Assume-se que as adolescentes engravidam por razões que 
lhes são próprias, tais razões, porém, precisam ser compreendidas em sua complexidade e não rotuladas como mera questão de opção.

\section{GRAVIDEZ NA ADOLESCÊNCIA}

Por tudo que foi dito, a gravidez na adolescência, sob a perspectiva Sócio-Histórica, deve levar em conta, entre outros aspectos, a condição social das jovens futuras mães. Neste trabalho, a investigação abordará adolescentes assistidas pelo SUS residentes na região metropolitana de Curitiba e usuárias do sistema público de educação.

Deve-se ressaltar que o fenômeno da gravidez na adolescência é uma questão complexa, portanto é necessário problematizar os discursos homogêneos relativos a esse tema, considerando-se a diversidade da situação econômica e social dos jovens brasileiros, Nesse sentido, Rohden (2007) faz uma análise aprofundada do tema, além de abordar a importância da sexualidade dos jovens, nos diferentes segmentos da sociedade, e aponta a evidência de que para os jovens de classes desfavorecidas, o exercício da sexualidade se traduz como uma forma de autonomização.

Uma breve retrospectiva histórica é suficiente para mostrar que, até a década de 40, no Brasil, era comum que meninas casassem e engravidassem em torno dos 15 anos de idade, aquelas que fugiam desse padrão, e chegavam, por exemplo, aos 18 anos sem se casar, eram encaradas com preocupação pela sociedade e podiam ser consideradas "solteironas" (Khahale, 2003). Foi só com a industrialização das cidades, iniciada ainda nos anos 30 e acelerada a partir dos anos 50, que a situação das jovens brasileiras se modificou, na medida em que a sociedade passou a atribuir importância à profissionalização decorrente do ingresso no mercado de trabalho. A independência econômica que começou, então, a ser conquistada pelas mulheres, contribuiu para a uma nova percepção sobre sua posição e participação na sociedade.

Muitas jovens, porém, dadas as desigualdades do modo de produção capitalista, não conseguiam, e ainda não conseguem, concluir adequadamente todas as etapas de profissionalização exigidas pelo mercado de trabalho. Elas se tornam o que Castel (1998) denomina "supranumerários", conceito que abrange os desfiliados sociais, isto é, as pessoas que não desempenham uma função social - pelo fato de não se inserirem no modo de produção vigente - e que, por esse motivo, vivem à margem da sociedade.

Diante dessa realidade muitas jovens encontram na gravidez um caminho, conforme exposto no trabalho de Joffily e Costa [s.d.] que revela a gravidez na adolescência como uma forma de solução para organizar suas vidas prática e afetiva, além de lhes proporcionar proteção social e familiar.

\section{PROJETO DE VIDA E GRAVIDEZ NA ADOLESCÊNCIA}

Sob a ótica da Psicologia Sócio-Histórica, a presença do outro é fundamental para a construção de um projeto de vida, na medida em que os aspectos individuais e coletivos estão presentes tanto na subjetividade dos adolescentes, quanto nas relações sociais. Para Molon (2003), o reconhecimento da identidade de uma pessoa é um processo dialético permanente; depende, assim, da existência de outro ser com quem o indivíduo se relaciona ao longo das diversas fases de sua vida. De acordo com essa perspectiva, o mundo, entendido em seus diversos sentidos - físico, biológico, imaginário, simbólico e social - é o lugar de construção da subjetividade.

Esse processo de formação da subjetividade está vinculado aos projetos de vida possíveis que são construídos a partir dos estereótipos, discursos e histórias de vida, compartilhados pelas pessoas desde sua infância, dentro de seus respectivos grupos sociais. É nesse contexto que a criança apreende a sua condição social e recebe de maneira impositiva normas e valores. Esses serão os elementos mantidos ou superados ao longo da elaboração de um projeto de vida que leve à construção de outras possibilidades de futuro (Catão, 2001).

D'Angelo Hernandez (2000) afirma que a forma peculiar como cada indivíduo fará determinadas escolhas, e as estratégias que adotará para alcançar seus objetivos, está necessariamente relacionada com o contexto social ao qual pertence. Para o autor, a construção de um projeto de vida, reflete uma relação dialética entre indivíduo e sociedade. No mesmo sentido Gonzalez Rey (2003) descreve esse tipo de relação dialética, nos seguintes termos:

Da perspectiva da subjetividade social, os processos sociais deixam de ser vistos como externos em relação aos indivíduos, ou mesmo como um bloco de determinantes consolidados, que adquirem o status do "objetivo" diante do subjetivo individual, para serem vistos como processos implicados dentro de um sistema complexo, a subjetividade social, da qual o indivíduo é constituinte e, simultaneamente, constituído. (p. 202)

Catão (2007) destaca a forte conexão entre os elementos psíquicos e sociais que moldam a identidade 
pessoal e os projetos de vida dos jovens. A autora afirma que a identidade pessoal se constrói a partir da relação com o mundo ao redor, com o passado e com o presente, tendo em vista o futuro. Há, portanto, uma relação entre projeto de vida e identidade pessoal, na medida em que o primeiro representa o lugar de interseção entre o aspecto psicológico da vida de cada um e as influências que recebe de seu ambiente social. O projeto de vida se constitui, assim, de acordo com a autora, no resultado da tensão dialética entre as realidades interna e externa coexistentes, que são vividas, pensadas e refletidas. $\mathrm{O}$ resultado desse processo permite que os indivíduos tentem transformar sua situação de vida presente rumo às almejadas mudanças futuras.

As reflexões e discussões relacionadas à construção de um projeto de vida demandam uma abordagem crítica da realidade. No caso das adolescentes grávidas, entende-se, que nesse processo, elas podem extrair, na medida de suas possiblidades, os meios para se tornarem protagonistas de suas próprias histórias, em vez de repetirem um enredo com o qual não estejam de acordo. Para tanto, é necessário que todo adolescente desenvolva a capacidade de lidar com conceitos abstratos, cujo domínio, de acordo com Vigotski (2010), somente pode ser alcançado em um local privilegiado: a escola, que desperta e aciona uma série de processos interiores de desenvolvimento, possibilitando maiores chances de conseguir traçar estratégias futuras consistentes, de forma crítica, favorecendo, portanto, que ele concretize seus objetivos.

\section{MÉTODO}

\section{Participantes}

Participaram da pesquisa dezesseis adolescentes grávidas com idades compreendidas entre 13 a 19 anos. Todas as adolescentes desse estudo são usuárias do SUS, estudam ou estudavam em escolas públicas e são moradoras de bairros situados na periferia de Curitiba. As idades gestacionais das adolescentes são variáveis, foram entrevistadas jovens que vinham para o atendimento médico, independentemente da condição de terem sido atendidas pela primeira vez pelo obstetra da maternidade onde se realizou a pesquisa. Das dezesseis adolescentes, nove iniciaram o atendimento pré-natal na maternidade onde foi feito este estudo, e sete vieram encaminhadas de outras unidades de saúde de Curitiba. Doze das adolescentes eram primigestas, três delas eram gestantes pela segunda vez e uma, gestante pela terceira vez. Em relação à situação conjugal das gestantes, constatou-se que uma delas era casada e vivia com o marido, duas viviam respectivamente com seus companheiros, três tinham namorados, mas não conviviam na mesma casa. Dez das entrevistadas, não tinham mais contato com os pais de seus filhos. O critério de exclusão adotado restringiu-se às idades das entrevistadas.

\section{Instrumentos}

Foram efetuadas entrevistas semiestruturadas de acordo com roteiro que contemplou aspectos da vivência da gravidez pelas adolescentes, tais como: projeto de vida antes da gravidez, planejamento da gravidez, situação de vida na época em que engravidou, reação pessoal à gravidez, reação da família à gravidez, percepção da gravidez pela adolescente e projeto de vida atual. As entrevistas foram realizadas na ocasião da primeira consulta de pré-natal de cada adolescente respectivamente. A duração média das entrevistas foi de uma hora.

\section{Procedimentos}

A pesquisa foi realizada em maternidade do SUS, referência em atendimento a adolescentes grávidas, na cidade de Curitiba. Cada adolescente gestante foi convidada a participar de uma entrevista, no mesmo dia em que compareceu ao atendimento médico prénatal, na sala do Serviço de Psicologia, contígua a do atendimento obstétrico. Os cuidados éticos foram observados: o projeto de pesquisa foi avaliado e aprovado por um comitê credenciado no Conselho Nacional de Ética em Pesquisa sob o número 5556/11 em 16 de junho de 2011. Todas as adolescentes entrevistadas receberam explicações prévias sobre a pesquisa, e em seguida assinaram o Termo de Consentimento Livre e Esclarecido. As entrevistas foram gravadas e posteriormente transcritas.

\section{RESULTADOS}

Os dados obtidos foram interpretados de acordo com a análise qualitativa de conteúdo descrita por Flick (2009), cuja característica principal é a utilização de categorias, obtidas a partir de modelos teóricos e direcionadas para o material empírico, com o objetivo de reduzi-lo a unidades conceituais que permitam uma análise científica. Nesse estudo, as categorias consideradas à priori foram: Projeto de Vida antes da Gravidez, Planejamento da Gravidez, Situação de Vida na Época em que Engravidou, Reação Pessoal à Gravidez, Reação da Família à Gravidez, Percepção da Gravidez pela Adolescente e Projeto de Vida Atual.

Os relatos das adolescentes foram divididos nas sete categorias mencionadas. A seguir, serão apresentados os resultados obtidos em cada um delas; em seguida 
os dados obtidos serão discutidos sob o viés da linha de compreensão adotada pela psicologia Sócio-Histórica.

\section{Projeto de Vida antes da Gravidez}

A primeira categoria abordada foi Projeto de vida antes da gravidez. Nessa categoria, foram identificados quais planos as futuras mães almejavam para as suas vidas antes de terem engravidado. Nove das entrevistadas declararam que pretendiam terminar os estudos e trabalhar. Seguem algumas das respostas obtidas a título de ilustração.

“Eu pensava em terminar os estudos primeiro né, ih... provavelmente fazer uma faculdade... mas, logo começar a trabalhar, pra guardar algum dinheiro ... pra poder estudar.. fazer uma faculdade..." (A. J. S., 18)

"Ah, era estudar e depois de estudar, ser professora de Educação Física, Mais dai né... engravidei..." (K.K.C.A., 13)

Quatro das jovens responderam que queriam engravidar:

"Era isso... era morar com o marido, igual que eu tô morando agora... e ficar grávida... engravidar dele e ficar com ele! (risos) só..." (D.D.L., 16)

Três adolescentes disseram que não tinham planos para o futuro. Uma das entrevistadas declarou: "Antes da gravidez eu num tava nem ai pra vida...".

\section{Planejamento da Gravidez}

A categoria Planejamento da gravidez buscou apurar como sua intencionalidade para engravidar era percebida pelas entrevistadas. Das dezesseis adolescentes ouvidas, treze responderam que não planejaram a gravidez, enquanto outras três responderam o contrário.

É importante destacar, porém, que cinco adolescentes mencionaram pretender engravidar em outro momento, bem como, uma das entrevistadas ter afirmado que não planejara a gravidez, mas acabou por aceitá-la, apesar de, no início da gestação, ter passado por um período de depressão.

"Eu fiquei apavorada! Porque minha mãe ficou mais ainda... Até o segundo mês, eu tava querendo entrar em depressão. Ainda bem que tô fazendo tratamento com psicóloga." (J.F.N., 14)

\section{Situação de Vida na Época em que Engravidou}

A categoria Situação de vida na época em que engravidou referiu-se às circunstâncias de vida das adolescentes, tanto nas esferas materiais como emocionais, na época em que engravidaram. Metade das adolescentes entrevistadas declarou que não enfrentava qualquer problema específico na época, enquanto a outra metade afirmou o contrário. Das entrevistadas que enfrentavam problemas, colheramse os seguintes depoimentos:

"Meu irmão mandava em mim, queria me levar pra balada pra me apresentar pros amigos dele. Ele andava com más companhias, que usavam drogas... Depois que eu engravidei, ele parou de querer me levar." (A.B.K., 15)

"Nossa! Tava virada! Tava virada de cabeça pra baixo...Tinha brigado com a minha mãe, dai fui morar com o meu pai. Mas, depois começou a se ajeitar.. Depois que eu descobri... que eu tava grávida." (J.M.I., 15)

\section{Reação Pessoal à Gravidez}

A análise das entrevistas indica que o espanto e o medo foram as reações iniciais mais comuns neste grupo, especialmente em razão da ansiedade provocada pelo fato de as gestantes não saberem como a gravidez seria recebida pela família. A fala de uma das adolescentes ilustra tais reações:

"Fiquei assustada... pensei: ai, a minha mãe vai me matar (ri) só que depois acabei falando com ela, ela me apoiou, tal..." (K.S.S., 15)

Na maioria dos casos, apurou-se ter havido aceitação posterior do fato consumado, tanto pelas gestantes quanto por seus familiares, os quais passaram a enfocar os aspectos positivos relacionados à gravidez.

Observou-se, tanto na categoria reação pessoal à gravidez quanto na reação da família à gravidez o efeito da falta do projeto de vida e, em consequência, mais uma vez, uma acomodação à situação vivenciada.

\section{Reação da Família à Gravidez}

A categoria Reação da família à gravidez investigou as diversas maneiras como as famílias das adolescentes reagiram, quando souberam que as jovens engravidaram, de acordo com a percepção das próprias gestantes. Dentro dessa perspectiva, as reações foram variadas: da felicidade à crítica seguida, da aceitação. 
Duas entrevistadas declararam terem sido acolhidas com felicidade. Uma delas comentou:

"Minha mãe ficou feliz. Disse que vai me ajudar a cuidar do bebê." (P.O.A., 18)

A maioria das entrevistadas, contudo, enfrentou críticas antes da aceitação. De acordo com uma das gestantes, a mãe reclamou dizendo que era muito cedo para que ela engravidasse. Outra adolescente disse que, a princípio, a mãe não aceitou o fato e que o pai ficou espantado com a ideia; no entanto, no momento da entrevista, ambos passaram a aceitar a gravidez:

"Minha mãe não gostou da ideia, no início... Mas, agora aceitou. Meu pai ficou meio espantado, mas como eu sou filha única ele gostou da ideia de ser vô." (J.N.I., 15).

Uma das entrevistadas mencionou que a reação da mãe foi de indiferença. Quando soube da notícia, falou que provavelmente ela também estivesse grávida:

“... A minha mãe não falou nada... ela falou bem assim, ah, eu acho que eu também tô... falou bem assim pra mim... dai eu falei bem assim, ô mãe, mas você já é muito véia pra ficar fazendo fio... dai ela assim... ah, daí? É juventú... ela falô bem assim..."(J.B.A., 14)

Por fim, outra adolescente disse que os pais aceitaram a gravidez com resignação:

"A minha mãe achou bom... porque eu queria... ah, ela nunca ia me tratá mal também... por causa que os pais dela rejeitaram a primeira gravidez dela, ela num ia tratá a mesma coisa comigo... meu pai aceitou, ele é mais calmo. meu pai tinha sonhado antes, que eu ia engravidar." (A.B.K., 15)

\section{Percepção da Gravidez pela Adolescente}

A categoria Percepção da Gravidez pela Adolescente teve como objetivo apurar a maneira como cada adolescente percebeu a experiência de se tornar mãe. As entrevistadas foram convidadas a refletir sobre a própria gravidez.

Nove das dezesseis entrevistadas não souberam responder à pergunta: "Qual o significado da gravidez para você?". Depois que lhes foi informado que o objetivo da questão era saber o que elas sentiam e pensavam sobre o fato de se tornarem mães, afirmaram, então, nunca terem refletido, até aquele momento, sobre o assunto - esse é um dado por si só significativo, pois a gravidez e os bebês que, forçosamente, vão tomar muito do tempo, recursos e possibilidades dessas jovens no futuro, pareciam não fazer parte dos seus horizontes até aquele momento.

Segue uma resposta, a título de ilustração:

"Não sei... (ri). Não sei explicar... Como pode? Uma criança sair da gente? Como é que pode, né? Ah! Sei lá... Não consigo explicar bem... Gosto de pensar que vou cuidar de um filho meu. Não parei ainda pra pensar..." (J.M.I., 15)

\section{Projeto de Vida Atual}

Na categoria Projeto de vida atual, as adolescentes responderam à pergunta sobre quais eram os seus planos para o futuro, em face da gravidez.

Nesse quesito, a maioria das adolescentes respondeu que pretendia retornar aos estudos assim que o bebê deixasse de exigir tantos cuidados. Nenhuma das jovens chegou a mencionar o desejo de receber algum tipo de apoio social que lhes ajudasse a concretizar esse projeto, como por exemplo: disponibilidade de creches nas próprias escolas que atendessem tanto aos trabalhadores dos educandários quanto às próprias alunas-mães. A seguir, como ilustração, segue a fala de uma das adolescentes: "Ainda eu não sei..., Agora (ri) eh... é cuidar do bebê né... dai depois, colocar numa creche pra mim trabalhá pra mim ficá melhor pra eu poder sustentar ele..." Duas, responderam que pretendem se dedicar ao filho e ao lar. Nas suas próprias palavras:

“Ah, eu penso só mesmo no nenêm... sabe? Só em fi vê ele, ficá com ele... participá de cada momento da vida dele... sabe? A minha vida agora é só ele... (ri). Na minha cabeça é só o nenêm... (ri)." (D.D.L., 16)

Uma jovem respondeu que não possuía planos para o futuro: "Ainda eu não sei..." (C.S.S., 14), outra entrevistada afirmou que pretendia trabalhar para dar à filha os bens materiais que ela própria nunca teve, tal comentário, por si mesmo, revela a carência de bens materiais, experimentada pela adolescente, mas indica também a ausência de questionamento sobre a causa da carência desses bens. A solução vislumbrada, então, limita-se ao desejo de conseguir um emprego que lhe permita suprir as necessidades materiais da família, sem abarcar a realidade social mais ampla, na qual o seu problema particular se encontra radicado. 


\section{DISCUSSÃO}

Em síntese os projetos de vida apurados nas entrevistas contemplavam essencialmente estudar e trabalhar, porém, as adolescentes não demonstraram conhecimentos consistentes com projetos de longo prazo, por exemplo: estratégias a adotar ou caminhos a serem trilhados para alcançar os objetivos pretendidos. Essa lacuna pode ser explicada pela ausência de um projeto de vida viável, pois este exige um exercício prático ao longo da vida, Nas palavras de Catão (2007): "pensar e refletir antes de praticar qualquer ação" (sem página). Nessas circunstâncias, a gravidez, que é um fato concreto, conhecido e previsível, termina por materializar-se à revelia das entrevistadas e, dadas as suas implicações práticas - parto, amamentação, cuidados com o bebê, mudanças na vida cotidiana etc. - passa a ocupar a posição de um projeto de vida inexistente ou traçado com linhas tênues.

Tais resultados ratificam a conclusão da pesquisa realizada na Universidade de Chicago (2011), com adolescentes afro-americanas, na qual se constatou que várias jovens responderam pretender aguardar de 5 a 10 anos para terem outro bebê e que a primeira gravidez não alteraria seus planos futuros, pois gestações adicionais no futuro seriam impeditivas para o alcance de seus objetivos. No entanto, durante o curso daquele estudo, observou-se que tais planos de longo prazo não se concretizaram no que diz respeito ao uso confiável de contraceptivos, confirmando a literatura que associa a reincidência de gravidez na adolescência a reduzidas perspectivas de realizações educacionais e profissionais.

No mesmo sentido, em estudo realizado na Nova Zelândia, Dickinson e Joe (2010) descrevem o processo de implantação e desenvolvimento de programa público de saúde que designa o atendimento grupal de adolescentes grávidas e jovens mães. O objetivo do programa era fornecer às adolescentes um espaço onde elas pudessem trocar experiências e criarem juntas, novos conhecimentos e, assim construir seu próprios projetos de vida. Para tanto, foram disponibilizadas informações e suporte jurídico. Como resultado, as mães relataram o aumento de autoestima e autoconfiança, da capacidade de expressarem suas necessidades, da habilidade de lidarem com seus bebês, de dirigirem suas vidas, de terem acesso a redes de apoio social e a serviços públicos, além de conseguirem ter perspectivas futuras positivas.

A pesquisa neozelandesa, assim, confirma a linha de pensamento do presente estudo, segundo a qual, ao se fornecer espaços para que as adolescentes possam se reunir em grupo com frequência constante e que lhes possibilitem trocar experiências, desenvolver um pensamento crítico e construir projetos de vida, possivelmente haverá maiores chances de que tais jovens consigam realizar escolhas e tomar decisões que lhes sejam favoráveis.

Gurgel et al. (2010) da mesma forma, ressaltam a importância do trabalho grupal com adolescentes, como estratégia para lhes propiciar o desenvolvimento de suas capacidades de reflexão crítica e autoconfiança, para, assim, poderem construir projetos de vida que lhes permitam fazer escolhas e tomarem decisões autênticas.

Quanto à questão de planejamento futuro, a presente pesquisa revelou predominantemente, uma ausência de planejamento para a maternidade entre as entrevistadas; alguns depoimentos, porém, indicam, de forma velada, que a gravidez, em si, converteu-se posteriormente em "projeto" de vida. "Projeto", aqui, aparece mais como justificativa do que como projeto de fato.

Pantoja (2003) salienta outro aspecto, segundo o qual, para algumas adolescentes, a gravidez consistiria em um projeto de vida peculiar que lhes permitiria o ingresso na vida adulta e, supostamente, uma ascensão social; entretanto, a realidade de descontinuidade nos estudos e consequente dificuldade de alcançar bons postos de trabalho, apontam para uma carência de articulação entre planos e ações que é resultado do repertório limitado de oportunidades que constitui a realidade das jovens entrevistadas. Nesse sentido, Heilborn et Aal. (2006) ressaltam que várias pesquisas descrevem os fatores que contribuem para o fenômeno da gravidez na adolescência, no entanto, não destacam o contexto social desfavorável, no qual a escola e um projeto de profissionalização não se mostram como alternativas mais viáveis ou atraentes do que a escolha pela parentalidade na adolescência.

Não se pode, a partir do conteúdo das entrevistas, concluir que a gravidez era a resposta aos problemas específicos enfrentados pelas adolescentes grávidas. No entanto, a ausência de problematização da realidade apurada nesta pesquisa indica a necessidade de as adolescentes desenvolverem uma visão crítica, essencial à construção de um genuíno projeto de vida. Nesse sentido, Paulo Freire (2011) afirma que é próprio da consciência crítica a sua integração com a realidade, ao contrário da consciência que ele denomina ingênua, a qual se superpõe fantasiosamente a ela, como parece ser o caso das adolescentes que acreditavam ingressar automaticamente no mundo adulto e resolver seus problemas cotidianos por meio da maternidade.

Várias adolescentes acabam idealizando a maternidade, como fonte de toda a felicidade; porém, 
Badinter (1980) analisa que o amor materno não é parte de um instinto natural, mas uma construção social e histórica. Ao contrário do senso comum atual, é tão imperfeito, incerto e frágil como qualquer outro sentimento. $\mathrm{Na}$ verdade, as maneiras de expressar dedicação e amor aos filhos variam conforme a época histórica e a classe social. A existência de um projeto de vida anterior à gravidez poderia ser o mecanismo pelo qual as adolescentes não sentiriam necessidade, diante da gestação em curso, de idealizar a maternidade e, assim, de convertê-la em sucedâneo para seus planos futuros.

Os sentimentos relacionados com a gravidez foram avaliados em pesquisa realizada por Godinho et al. (2000) que chegou a resultado semelhante: metade das adolescentes grávidas entrevistadas justificou o desejo de engravidar alegando gostar de crianças. Entretanto, ao expressarem seus sentimentos, demonstraram "baixo envolvimento com a realidade". Joffily e Costa [s.d.] afirmam que não se pode falar em homogeneidade de sentimentos que tanto podem ser positivos, de felicidade, quanto negativos, medo, ansiedade, etc. As autoras alegam que no $2^{\circ}$ trimestre costuma ocorrer uma aparente aceitação da gravidez.

As pesquisas realizadas sobre o tema parecem indicar que a ideologia dominante, no meio em que vivem as gestantes, induz a aceitação da gravidez, que passa a ocupar circunstancialmente a lacuna de um projeto de vida construído de forma reflexiva.

Catharino e Giffin (2002) constatam em entrevistas com gestantes adolescentes que a maioria não planejou a gravidez; as entrevistadas, contudo, declararam ter ficado felizes quando souberam que estavam grávidas a despeito de também manifestarem sentimentos divergentes - surpresa e temor - principalmente, por anteverem uma reação negativa das famílias e dos namorados. Essa situação se convertia em algo muito desejado no momento em que a gravidez era acolhida pelos familiares.

Hoga et al. (2010) referem que as famílias das adolescentes reagiram diferentemente em relação à constatação da gravidez, no entanto, geralmente ocorre uma redefinição das relações familiares com o propósito de superar as dificuldades financeiras e conflitos familiares.

Tais resultados corroboram a constatação de que tanto a adolescente, em primeiro lugar, quanto as suas famílias, em seguida, são surpreendidas por uma realidade não planejada que determinará substancialmente os rumos a serem seguidos a partir de então, retirando-lhes autonomia para decidir ações futuras.

Joffily e Costa [s.d.] também constataram, em seu estudo, que as adolescentes que já tinham dado à luz não atribuíam relevância ao período da gestação, nem conseguiam descrevê-lo. Somente a partir do parto é que a situação concreta cobrava alguma reflexão das jovens mães. As autoras chegam a mencionar que essas jovens referiam-se à gestação como "nada de mais" ou algo "normal", termos tomados como sinônimos, e avaliam que, na linguagem das jovens, essas expressões podem indicar muitas coisas aparentemente contraditórias. Tais resultados coincidem com as respostas aqui obtidas. Mais da metade das adolescentes não havia, até a entrevista, refletido sobre a gestação em si, o que parece indicar uma dificuldade de lidar com situações e conceitos abstratos, a gravidez em si, antes do nascimento dos bebês. Nesse sentido, Joffily e Costa [s.d.] destacam que o parto consiste no momento de passagem do "filho imaginário" para o "filho realidade" e, em consequência, como marco da elaboração de projetos específicos para o futuro, conforme será visto a seguir.

Catharino e Giffin (2002), igualmente, registram como perspectivas futuras - mencionadas por jovens grávidas - a constituição de nova família, a criação e o cuidado dos seus bebês e a construção de uma casa própria. Também verificaram que a gravidez é percebida, tanto pelas próprias adolescentes, quanto por suas famílias, como uma "ruptura ou desvio de rota" devido à idade precoce. Entretanto, como visto, não havia um projeto de vida efetivamente articulado, apenas anseios vagamente definidos, como por exemplo: concluir os estudos. As autoras apontam um elevadíssimo percentual de fracasso: $96 \%$, no projeto acalentado pelas jovens mães de retornar aos estudos, provocado pela necessidade de começar a trabalhar.

Percebe-se, ainda, que muitas adolescentes tomam para si, exclusivamente, a responsabilidade por terem engravidado. Catharino e Giffin (2002) chegam a mencionar o sentimento de culpa, que é mitigado pelo plano de voltar à escola. As jovens mães, porém, não concebem as possibilidades e direitos adquiridos que lhes facultariam concluir seus projetos de vida e lutar por outros direitos não diretamente relacionados com a gravidez.

Godinho et al. (2000) relatam a forma idealizada como as jovens grávidas se referem à própria gravidez e aos seus desdobramentos, permanecendo alheias aos problemas cotidianos concretos, tais como; seu próprio sustento, estudo, trabalho, realização pessoal. Segundo os autores, muitas adolescentes não avaliam de forma consistente as dificuldades que possivelmente enfrentarão para se inserirem no mercado de trabalho e terem condições econômicas de sustentarem a si mesmas e a seus respectivos bebês. Elas fazem planos de voltarem aos estudos sem levar em conta o possível 
aumento das dificuldades diante da responsabilidade de cuidar de uma criança. Além disso, raramente mencionam o desejo de se realizarem pessoalmente no campo profissional. Pode-se, portanto, constatar que não apresentam alternativas realistas para enfrentar a nova realidade da maternidade.

Silva et al. (2009) indicam a forma superficial com que as puérperas adolescentes se referem aos significados por elas atribuídos à maternidade. Em geral, mencionam apenas os aspectos relacionados aos cuidados físicos dos bebês, não revelaram dados subjetivos relacionados ao fato de terem se tornado mães.

Para Catão (2007), o projeto de vida pode ser compreendido como a síntese entre uma realidade negada e outra nova que se dá pela superação promovida pela atividade do sujeito. De acordo com a autora, nas dimensões Psico-sócio-históricas, um projeto de vida é construído a partir da práxis, da relação com o outro e consigo mesmo. Traz embutido dentro dele uma intenção de transformar a realidade, que é, por sua vez, guiada por uma representação de sentido dessa transformação calcada nas condições reais da existência.

A construção de um projeto de vida, portanto, favorece o exercício de uma relação não idealizada com a realidade, condição necessária para o enfrentamento e superação das novas condições de vida das futuras mães.

\section{Considerações Finais}

A construção de um projeto de vida é algo complexo e implica a conjunção de diversos fenômenos, dentre os quais se encontram: a identidade pessoal e a relação dialética entre sujeito e sociedade (Nascimento, 2006; Catão, 2007; D’Angelo Hernandez, 2000; Ciampa, 2004).

Além desses fatores, devem ser mencionadas também as perspectivas que a sociedade oferece ao sujeito e a possibilidade de ele realizar uma análise crítica, histórica e social sobre o passado e presente do grupo social a que pertence.

Desse modo, para que a adolescente construa o seu projeto de vida de forma crítica e realista é necessário que ela desnaturalize a forma como o senso comum interpreta a realidade. Desnaturalização, essa, entendida como a revelação das contradições impostas por interesses sociais e políticos a determinados fatos e relações que limitam a capacidade de compreensão e de superação da situação presente (Montero, 2008).

Muitas dessas adolescentes, conforme visto, reproduzem acriticamente modelos femininos de suas mães, que também, em muitos casos, engravidaram na adolescência. Tal situação indica a ausência de espaços onde as adolescentes possam refletir e articular novos elementos aos seus projetos de vida, criar novos caminhos e não apenas reproduzir os já conhecidos.

Como visto, a maioria das entrevistadas respondeu que pretendia, assim que possível, terminar os estudos - o ensino médio - e trabalhar. No entanto, nenhuma delas questionou a situação social e familiar na qual viviam e vivem, portanto, não utilizaram o tema abordado para fazerem algum tipo de questionamento e reavaliações da realidade.

Sem espaços de reflexão e introdução de novos elementos na criação de seus projetos de vida, para as adolescentes, que se encontram na condição de supranumerários, a maternidade se converte em um precário projeto construído após a constatação da gravidez, e mais concretamente após o parto.

A ausência de escolas capazes de oferecer uma formação de qualidade às jovens grávidas, que lhes permita lidar com conceitos abstratos, as impede de realizar a síntese dialética necessária à construção de um projeto de vida realista. Essa síntese deve reunir, conforme Catão (2007), a realidade concreta da vida e os conceitos abstratos, denominados por Vigotski (2010) conceitos científicos. O resultado dessa síntese: o projeto de vida, serve como instrumento para evitar "desvios de rota", previsíveis e controláveis, como a gravidez não planejada, ou o cultivo de quimeras como se revelam os "projetos" de retorno aos estudos, meros fatos desejados sem apreciação crítica.

Esse fato sugere que algumas das adolescentes entrevistadas aceitaram, com naturalidade, a postergação dos seus planos de estudo para poderem se dedicar aos cuidados de seus bebês. Apesar de quase todas afirmarem pretender voltar a estudar, não demonstraram preocupação com a interrupção provocada pela gravidez. Essa constatação sugere a necessidade de seja questionado o tipo de vínculo que a escola estabelece com as adolescentes, a ponto de sua ausência imediata não ser, para elas, fundamental. A mesma indiferença - quanto à continuidade dos estudos - aparece nas respostas das adolescentes que declararam ter a maternidade como projeto de vida. Parece que tal indiferença expressa um sentimento de desesperança em relação à vida escolar como algo, no mínimo, interessante.

Ratificam-se, assim, as proposições de Bock e Liebesny (2003), sobre um comportamento conservador das jovens, na medida em que não questionam a parcela de responsabilidade social presente nas dificuldades que enfrentavam, limitando-se a reproduzir a forma de viver dos adultos ao seu redor. Não se quer com isso atribuir responsabilidade por esse conservadorismo 
às próprias adolescentes, mas às condições sociais e históricas que determinam as poucas opções de futuro disponíveis para essas jovens.

De modo semelhante, esta pesquisa indica que a ausência de um projeto de vida consistente reflete as condições materiais das entrevistadas e pode converter a gravidez em projeto de vida alternativo. Espaços de discussão e reflexão são necessários para facultar a essas jovens a possibilidade de fazerem escolhas autênticas.

Uma limitação do presente estudo consiste na investigação dos projetos de vida anteriores à gravidez, em um momento no qual as adolescentes já são gestantes. Tal situação pode ter interferido na elaboração das respostas dadas, tendo em vista que a gravidez já se tornara uma realidade concreta, no momento das entrevistas. Do mesmo modo, seria possível esperar interferência nas respostas se a entrevista fosse efetuada após o nascimento dos bebês. Portanto, compreendese que os dados obtidos nesta pesquisa refletem um momento específico da vida das entrevistadas. A pesquisa poderia ser ampliada pela coleta de dados em diferentes momentos, como no início da gravidez e no puerpério. Também caberia pesquisar os projetos de vida de adolescentes que não estivessem grávidas e analisar as semelhanças e diferenças, se constatadas, entre eles. Pode-se perceber que a presente pesquisa abre uma ampla gama de possibilidades de estudo capazes de enriquecer o tema.

\section{REFERÊNCIAS}

Badinter, E. (1980). Um amor conquistado: o mito do amor materno. [groups-beta google.com/group/digitalsourse]. Recuperado em 12 de novembro de 2012. Obtido em http://www.fiocruz.br/ redeblh/media/livrodigital\%20(pdf)\%20(rev).pdf

Belo, M. A. V., \& Silva, J. L. P. (2004). Conhecimento, atitude e prática sobre métodos anticoncepcionais entre adolescentes gestantes. Revista Brasileira de Saúde Pública, 38, 479-487.

Bock, A. M. B. (2009). A psicologia sócio-histórica: uma perspectiva crítica em psicologia. In A. M. B. Bock, M. G. M. Gonçalves, \& O. Furtado (Org.). Psicologia sócio-histórica: uma perspectiva crítica em psicologia (4 $4^{\mathrm{a}}$ ed.) (pp. 15-35). São Paulo: Cortez.

Bock, A. M. B., \& Liebesny, B. (2003). Quem eu quero ser quando crescer: um estudo sobre projeto de vida de jovens em São Paulo. In S. Ozella (Org.). Adolescências construídas: a visão da psicologia sócio-histórica (pp. 203-222). São Paulo: Cortez.

Brandão, E. R., \& Heilborn, M. L. (2006). Sexualidade e gravidez na adolescência entre jovens de camadas médias do Rio de Janeiro, Brasil. In Cad. Saúde Pública, Rio de Janeiro, 22(7), 1421-1430, jul, 2006, recuperado em 30 de março de 2014 e obtido em: http://www.scielosp.org/pdf/csp/v22n7/07.pdf

Carvalho, G. M., Merighi, M. A. B., \& Jesus, M. C. P. (2009). Recorrência da parentalidade na adolescência na perspectiva dos adolescentes envolvidos. Recuperado em 07 de dezembro de 2012. Obtido em http://www.scielo.br/pdf/tce/v18n1/v18n1 a02.pdf
Castel. R. (1998). As metamorfoses da questão social: uma crônica do salário ( $3^{\mathrm{a}} \mathrm{ed}$.). Petrópolis: Vozes.

Catão, M. F. M. (2001). Projeto de vida em construção: na exclusão/ insersão social. João Pessoa. UFPB/Editora Universitária.

Catão, M. F. M. (2007). O que pedem as pessoas da vida e o que desejam nela realizar. Recuperado em 13 de setembro de 2012. Obtido em http://projetodevida-projetodevida. blogspot.com. br/2011/09/artigo.html

Catharino, T. R., \& Griffin, K. (2002). Gravidez e adolescência: investigação de um problema moderno. Recuperado em 13 de setembro de 2012. Obtido em http://www.abep.nepo.unicamp.br/ docs/anais/pdf/2002/Com_JUV_ST7_Catharino_texto.pdf

Ciampa. A. C. (2004). Identidade. In T. M. Silvia, \& W. C. Lane (Org.). Psicologia social: o homem em movimento ( $4^{\mathrm{a}}$ ed.) (pp. 58-75). São Paulo: Brasiliense.

Dadoorian, D. (2003). Gravidez na adolescência: um novo olhar. Psicologia, Ciência e Profissão, 23(1), pp. 84-91.

D'Angelo Hernandez, O. S. (2000). Proyecto de vida como categoria básica de interpretación de la identidad individual y social. Rev. Cuba. Psicol., La Habana, 17(3). Recuperado em 06 de dezembro de 2012. Obtido em http://pepsic.bvsalud.org/18scielo. php?script=sci_arttext\&pid=S0257-43222000000300008\&lng= pt\&nrm=iso

Dickinson, P., \& Joe, T. (2010). Strengthening Young mothers. A qualitative evaluation of a pilot support group program. In Youth Studies Australia, 29(1). Recuperado em 30 de março de 2014. Obtido em http://www.acys.info/ysa/issues/authors/i-1/joe,_t./ strengthening_young_mothers/youngmothers.pdf.

Flick, U. (2009). Introdução à pesquisa qualitativa ( $3^{\mathrm{a}}$ ed.). Porto Alegre: Artmed.

Freire, P. (2011). Educação como prática da liberdade (14 ${ }^{\mathrm{a}} \mathrm{ed}$. rev. e atual.). Rio de Janeiro: Paz e Terra.

Godinho, R. A., Schelp, J. R. B., Parada, C. M. G. de L., \& Bertoncello, M. M. F. (2000). Adolescentes grávidas: onde buscam apoio? Revista Latino Americana de Enfermagem, Ribeirão Preto-SP, 8(2), 25-32. Recuperado em 13 de setembro de 2012. Obtido em www.scielo.br/pdf/rlae/v8n2/12414.pdf

Gonzalez Rey, F. L. (2003). Sujeito e subjetividade: uma aproximação histórico-cultural. São Paulo: Thomson.

Gurgel, M. G. I., Alves, D. S., Moura, E. R. F., Pinheiro, P. N. da C., \& Rego, R. M. V. (2010). Desenvolvimento de habilidades: estratégia de promoção da saúde e prevenção da gravidez na adolescência. Recuperado em 30 de março de 2014. Obtido em http://www.scielo.br/scielo.php?script=sci_arttext\&pid= S1983-14472010000400005

Joffily, S. M. L. de C. \& Costa, L. F. [s.d.]. É possível prevenir gravidez na adolescência? Recuperado em 16 de maio de 2011. Obtido em http://www.psicologia.pt/artigos/textos/ A0231.pdf

Heilborn, M. L., Cabral, C. S., Bozon, M., \& Grupo Gravad. (2006). Gênero e carreiras sexuais e reprodutivas de jovens brasileiro. Recuperado em 30 de março de 2014. Obtido em: http://www.abep. nepo.unicamp.br/encontro2006/docspdf/abep2006_607.pdf

Hoga, L. A. K., Borges, A. L. V., \& Reberte, L. M. (2010). Razões e reflexos da gravidez na adolescência: narrativas dos membros da família. Recuperado em 30 de março de 2014. Obtido em http://www.scielo.br/pdf/ean/v14n1/v14n1a22

Kafrouni, R. (2009). A dimensão subjetiva da vivência de jovens em um programa social: contribuições à análise de politicas públicas para a juventude. Tese de Doutorado em Psicologia Social, Pontifícia Universidade Católica de São Paulo. PUC-SP. São Paulo.

Loss, M. A., \& Sapiro, C. M. (2005). Processos psíquicos do engravidamento na adolescência em contextos de periferia: impasses e possibilidades. Psicologia USP, 16(4), 633-639.

Molon, S. I. (2003). Subjetividade e constituição do sujeito em Vygotsky. Petrópolis, RJ: Vozes. 
Montero, M. (2008). Introducción a la psicología comunitaria: desarollo, conceptos y procesos. Buenos Aires: Paidós.

Nascimento, I. P. (2006). Projeto de vida de adolescentes do ensino médio: um estudo psicossocial sobre suas representações. Recuperado em 06 de dezembro de 2012. Obtido em http:// www.revistasusp.sibi.usp.br/scielo.php?pid=S1413-666X 2006000100004\& script $=$ sci arttext

Ozella, S. (2003). A adolescência e os psicólogos: a concepção e a prática dos profissionais. In S. Ozella (Org.). Adolescências construídas: a visão da psicologia sócio-histórica (pp. 17-40). São Paulo: Cortez.

Pantoja, A. L. N. (2003). "Ser alguém na vida": uma análise sócio-antropológica da gravidez/maternidade na adolescência, em Belém do Pará, Brasil. Cad. Saúde Pública, 19(Sup. 2), S335-S343.

Rangel, D. L. O., \& Queiroz, A. B. A. (2008). A representação social das adolescentes sobre a gravidez nesta etapa de vida. Escola Anna Nery, 12(4), 781-789. Recuperado em 07 de dezembro de 2012. Obtido em http://www.scielo.br/scielo.php?pid=S141481452008000400024\&script=sci_arttext

Rohden, F. (2007). Gravidez na adolescência, um debate contemporâneo. Recuperado em 30 de março de 2014. Obtido em $\mathrm{http}: / /$ portalmultirio.rio.rj.gov.br/sec21/chave_artigo.asp? cod artigo $=1000$

Silva, L. A da, Nakano, A. M. S., Gomes, F. A., \& Stefanello, J. (2009). Significados atribuidos por puérperas adolescentes à maternidade: autocuidado e cuidado com o bebê. Recuperado em 30 de março de 2014. Obtido em: http://www.scielo.br/ scielo.php?script=sci_arttext\&pid=S0104-07072009000100006
Vigotski, L. S. (2010). Desenvolvimento dos conceitos cotidianos e científicos na idade escolar. In Psicologia pedagógica ( $3^{\mathrm{a}} \mathrm{ed}$.) (pp. 517-545). São Paulo: Martins Fontes.

Villela, W. V., \& Doreto, D. T. (2006). Sobre a experiência sexual dos jovens. Cad. Saúde Pública, 22(11), 2467-2472. Recuperado em 10 de outubro de 2012. Obtido em http://www.scielo.br/pdf/ csp/v22n11/21.pdf

Universidade de Chicago, Family planning, \& Contraceptive research. (2011). Future Goals of Adolescent Mothers. Recuperado em 30 de março de 2014. Obtido em http://familyplanning. uchicago.edu/research/studies-by-topic/postpartum-abcs/Goals. pdf

Autores:

Sara Kudlowiez - Psicóloga do Hospital de Clínicas da Universidade Federal do Paraná com Mestrado em Psicologia Social Comunitária pela Universidade Tuiuti do Paraná (2013).

Roberta Kafrouni - Doutora em Psicologia Social pela Pontifícia Universidade Católica de São Paulo (2009). Mestre em Psicologia Social Comunitária pela Universidade Federal do Paraná (2002).

Endereço para correspondência:

Sara Kudlowiez

Hospital de Clínicas - UFPR

Rua General Carneiro, 181 - Alto da Glória

CEP 80060-900 Curitiba, PR, Brasil

Tel.: (41)9949-9008

E-mail: sara.kudlowiez@gmail.com

Recebido em: 03.07.2013

Aceito em: 22.01.2014 